\title{
Diversity of Arbuscular Mycorrhizae Fungi from Orchard Ecosystem
}

Angaleswari Chandrasekeran*and P.U.Mahalingam

Department of Biology, Gandhigram Rural Institute-Deemed University, Dindigul, Tamil Nadu, India

*Corresponding author: Angaleswari Chandrasekeran, Department of Biology,

Gandhigram Rural Institute - Deemed University, India; Tel: 0451-2452371-75; E-mail: esdhanu@gmail.com

Rec date: May 5, 2014; Acc date: May 29, 2014; Pub date: June 5, 2014

Copyright: (c) 2014. Chandrasekeran A, et al. This is an open-access article distributed under the terms of the Creative Commons Attribution License, which permits unrestricted use, distribution, and reproduction in any medium, provided the original author and source are credited.

\begin{abstract}
Arbuscular mycorrhizal fungi (AMF), a symbiotic microorganism survives in both soil and roots. $80 \%$ of the plant roots acts as the host for the AMF and they are known as the component of soil and functional links between soil and plant. Orchard ecosystem was selected for the study since they are having a diversified plant flora. Roots and rhizosphere soil samples were collected randomly from Rosa indica, Citrus lemon, Emblica efficinalisis, Punica granutum, Mangifera indica orchard located at Gandhigram Rural Institute-Deemed University, Gandhigram, Dindigul, Tamil Nadu, India. The samples were processed for the presence of AMF in both roots and soil. Wet sieving and decanting method was followed for the isolation of AMF from soil and trypan blue staining was carried out for roots. The mean percent colonization in roots and mean spore population was calculated for a period four months from December 2011 to March 2012. The monthly variation in AMF spore population and root colonization were recognized from the datas obtained. The abundance of AMF is from two families viz., Glomus (G.aggregatum, G.fasiculatum, G.mosseae and Acaulospora (Acaulospora sp)).
\end{abstract}

Keywords: Orchard ecosystem; Diversity; Glomus sp; Acaulospora $s p$.

\section{Introduction}

In recent years, there has been increasing evidence that the microbial communities of soil and plants have an important role in the development of sustainable agriculture. Among the microorganism living in the rhizosphere of plants, the arbuscular mycorrhizal fungi have been found to be essential components of sustainable soil-plant systems. AMF are one of the most abundant underground symbioses, since AMF could colonise more than $80 \%$ of the higher plants [1].

The mycorrhizal symbiosis is a natural relationship between plant roots and fungi that can enhance plant growth, reduce plant nutrient requirements, increase survival rate and development of plants, improve plant resistance to abiotic and biotic stresses, enhance crop uniformly and increase fruit production $[2,3]$.

AMF are common root colonizing fungi that form symbiotic association with higher plants [4-6]. Although these fungi are obligate symbionts they are not host specific and one species may be found to be associated with various plants in the same locality. Also one host plant can support mixed populations of AMF species [7].

The importance of mycorrhizal fungi diversity and ecosystem functioning is now being recognized, particularly with respect to their potential to control plant diversity and productivity [8]. There is also a growing understanding in the role of the plant community in determining the structure of mycorrhizal fungal communities $[9,10]$. Hence the present work focuses on the diversity of arbuscular mycorrhizae fungal diversity in orchard ecosystem. Since orchard ecosystem consists of diversified plants the work was carried out with the diverse samples which would fulfill the relationship between plant and mycorrhizal fungal communities which play a fundamental role in determining the species composition and diversity of both plant and fungal communities.

The objective of the study is to collect random samples viz., roots and rhizosphere soil and processing of the same for the diversity studies from five plants viz., Rosa indica, Citrus lemon, Emblica efficinalisis, Punica granutum, Mangifera indica during the period December 2011 to march 2012.

\section{Materials and Methods}

\section{Collection of sample}

Random sampling method was employed. Roots and all associated rhizosphere soil samples were collected from five different plants viz., Rosa indica, Citrus lemon, Emblica efficinalisis, Punica granutum, Mangifera indica at a depth of $5 \mathrm{~cm}$ to $10 \mathrm{~cm}$. The number of samples collected was based on the number of dominant crops in the field. The collected root samples were washed with water and fixed in FAA (Formalin-Acetic acid-Alcohol) solution and soil samples were transferred in aseptic container to the laboratory, Department of Biology, Gandhigram Rural Institute-Deemed University, Gandhigram, Dindigul, Tamil Nadu.

\section{Estimation of Arbuscular Mycorrhizae Fungi colonization in roots}

The roots fixed in FAA were washed thoroughly in tap water but not vigorously enough to detach the external hyphae. The roots were placed in $250 \mathrm{ml}$ beaker and $10 \% \mathrm{KOH}$ was added to it. This mixture was boiled at $90^{\circ} \mathrm{C}$ for 30 minutes to $1 \mathrm{hr}$. After boiling the $\mathrm{KOH}$ solution was poured off and the roots were thoroughly washed with tap water for three times. The roots were immersed $30 \% \mathrm{H}_{2} \mathrm{O}_{2}$ for 3-5 minutes until the roots get bleached. Then the roots were washed with tap water followed by acidification with $5 \mathrm{~N} \mathrm{HCl}$ for 3-4 minutes and 
Page 2 of 4

stained with $0.05 \%$ trypan blue. After staining the root samples were cut into equal pieces of $1 \mathrm{~cm}$ length, 10 bits per slide was kept using lactophenol cotton blue as mounting medium and examined under low power microscopy for hyphae and high power microscopy for vesicles and arbuscles [11-13].

\section{Isolation of AMF from Rhizosphere soil}

Common technique for isolation of the arbuscular mycorrhizae spores from soil [14] is based on wet sieving and decanting [15]. In order to isolate the fungal spores, a series of sieves were used [16]. $50 \mathrm{~g}$ of rhizosphere soil samples was air dried, $500 \mathrm{ml}$ of water was added and a magnet was placed on a magnetic stirrer for 5 minutes. The flask was kept in stasis for 45 seconds until the heavier particles are deposited and immediately, the supernatant was poured ( 3 times to completely drain the contents of the flask) on a series of sieves, with mesh sizes of 25, 50 and 100. The slag's on the sieve were washed with sufficient amount of water. Eventually, the remainder of the top sieve 100,50 and 25 micrometers were collected separately and poured onto the graded filter paper No. 1 and spores were counted [15]. The shape and frequency of spores were observed using binocular microscope and were preliminarily identified using INVAM website and Research results [17]

\section{Identification of AMF}

Identification of AMF from the rhizosphere soil samples were done with the standard keys.

Taxonomy of VAM fungi $[18,19]$

Manual for the identification of VAM fungi [14]

Taxonomy of VAM fungi, classification, nomenclature \& identification [18]

Revised classification of AMF [19]

\section{Results}

Roots and rhizosphere soil samples from the orchard was collected from Gandhigram Rural Institute-Deemed University, Gandhigram, Dindigul, Tamil Nadu, India during the period of December 2011March 2012. The five samples collected were processed for recording percent root colonization and spore population. The results were tabulated in table.

\begin{tabular}{|l|l|l|l|l|l|}
\hline S.No & Sample & $\begin{array}{l}\text { Decembe } \\
\text { r 2011(\%) }\end{array}$ & $\begin{array}{l}\text { January } \\
\mathbf{2 0 1 2}(\%)\end{array}$ & $\begin{array}{l}\text { February } \\
\mathbf{2 0 1 2}(\%)\end{array}$ & $\begin{array}{l}\text { March } \\
\mathbf{2 0 1 2}(\%)\end{array}$ \\
\hline 1 & Rosa indica & 48.8 & 17 & 49.7 & 47.9 \\
\hline 2 & Citrus lemon & 40 & 21 & 53.2 & 52.1 \\
\hline 3 & Emblica efficinalisis & 49.1 & 22.2 & 63.1 & 53.7 \\
\hline 4 & Punica granutum & 50.2 & 25.2 & 52.7 & 50.4 \\
\hline 5 & Mangifera indica & 46.8 & 26.9 & 54.7 & 51.7 \\
\hline & Total & 234.9 & 112.3 & 273.4 & 255.8 \\
\hline & Mean & 46.98 & 22.46 & 54.68 & 51.16 \\
\hline
\end{tabular}

Table 1: Mean percent root colonization of AMF in the root samples
The rhizosphere soil samples collected under five different root zones in the orchard, GRI, Gandhigram, Dindigul, Tamil Nadu were processed for identification of AMF population and the results were presented in the Tables 1-3.

\begin{tabular}{|l|l|l|l|l|l|}
\hline S.No & Sample & $\begin{array}{l}\text { December } \\
\mathbf{2 0 1 1}(\%)\end{array}$ & $\begin{array}{l}\text { Janua } \\
\text { ry } \\
\mathbf{2 0 1 2} \\
\mathbf{\%}) \\
(\%)\end{array}$ & $\begin{array}{l}\text { February } \\
\mathbf{2 0 1 2 ( \% )}\end{array}$ & $\begin{array}{l}\text { March } \\
\mathbf{2 0 1 2} \\
\mathbf{( \% )}\end{array}$ \\
\hline 1 & Rosa indica & 38.3 & 40.7 & 87.6 & 73.4 \\
\hline 2 & Citrus lemon & 44.6 & 23.9 & 64.3 & 59.8 \\
\hline 3 & $\begin{array}{l}\text { Emblica } \\
\text { efficinalisis }\end{array}$ & 46.0 & 35.1 & 70.9 & 69.4 \\
\hline 4 & Punica granutum & 34.2 & 20.9 & 72.4 & 71.2 \\
\hline 5 & Mangifera indica & 28.0 & 29.2 & 78.9 & 63.7 \\
\hline & Total & 191.1 & 149.8 & 374.1 & 337.5 \\
\hline & Mean & 38.22 & 29.96 & 74.82 & 67.5 \\
\hline
\end{tabular}

Table 2: Mean spore population of AMF in the rhizosphere soil sample

\begin{tabular}{|l|l|l|}
\hline S.No & AM fungi & Family \\
\hline 1 & Glomus aggregatum & Glomaceae \\
\hline 2 & Glomus fasiculatum & Glomaceae \\
\hline 3 & Glomus mosseae & Glomaceae \\
\hline 4 & Glomus sp & Glomaceae \\
\hline 5 & Acaulospora $s p$ & Acaulosporaceae \\
\hline
\end{tabular}

Table 3: List of AMF recorded in orchard ecosystem

\section{Discussion}

In the present study diversity of mycorrhizae fungal flora in the orchard ecosystem, Gandhigram Rural Institute-Deemed University, Gandhigram, Dindigul was investigated. Genus and species level identifications were made which results in five different species of AMF recorded during December 2011-March 2012. The study revealed that all the root samples and rhizosphere soil samples had AMF association but varied in percent colonization and population. Maximum percent root colonization was recorded by Emblica efficinalisis (63.1) during Feb. 2012-Mar 2012 followed by Mangifera indica (54.7) during Feb. 2012-Mar 2012 and the maximum mean spore population of AMF in rhizosphere soil was recorded by Rosa indica (87.6) during Feb. 2012 to Mar 2012 followed by Mangifera indica (78.9) during Feb. 2012-Mar 2012. The result infers that the root samples and rhizosphere soil samples had maximum AMF population in all the five samples screened during Feb 2012-Mar 2012.

This observation obviously showed the occurrence of AM fungi within the roots and the mean percentage root colonization of AMF increased from February to march, which corroborates previous studies in other crops such as cassava [20,21]. Seasonal changes affected AM spore numbers which were observed to be higher in the dry season and lower during the rainy season. The level of spore 
Page 3 of 4

numbers is known to be affected by soil moisture content was also reported [5]. AMF survivals are known to be resistant to adverse environmental conditions [22], it is expected that more spores will be found in soils under such unfavorable climatic conditions and hence the present works observation was maximum during the dry season.

There were four dominant species (G.aggregatum, G. fasiculatum, G.mosseae) in Glomus and one species in Acaulospora respectively. Though the species diversity of Acaulospora (1 species) was less than Glomus (4 species), high isolation frequency and abundance was noticed in the orchard ecosystem. G.aggregatum, frequently occur inside roots [23], also this fungus has been known for its frequency in occurrence [24]. G.fasiculatum indicates that some species are facultative symbionts [25]. G.mosseae is a frequent component of communities of arbuscular mycorrhizal fungi associated with plants of different regions [26]. Acaulospora $s p$ are probably a widely distributed arbuscular mycorrhizal fungus in the world in both cultivated and uncultivated soils [27].

Arbuscular mycorrhizae (AM) are ubiquitous symbioses between plant roots and AM fungi in terrestrial ecosystems. AM fungi extend their waved mycelial network to everywhere, which combines plenty of plant individuals to make a large functional organism. The mycelial network of AM fungi provides a greater absorptive surface than root hairs and thus is helpful for the plants to absorb nutrition in soil, particularly phosphorus. The AM fungal community influences the course of plant succession, affects plant community diversity and productivity (and has a strong influence on ecosystem function) [28].

The dominance of AM fungal genera in the orchard ecosystem may be related to their sporogenous characteristics. Glomus and Acaulospora possess the smallest size spores in AM fungi taxa. Small spores are easy to distribute and produce a large number of spores in a short time [29]. Though Glomus constitutes the most fungal species (4 species of 5) in this study, one species in Acaulospora are distributed widely in the sampling area and produce more spores.

Wide distribution and a strong capacity of sporulation usually exist concurrently in dominant species [30,31]. But in this study, the dominant species of G.aggregatum, G. fasiculatum, G.mosseae were found to be widely distributed in root samples rather than their abundance in soil. It has been reported that, because of their strong mycelium network that spreads among host plants in a large area and producing fewer spores, some Glomus species spores may be relatively infrequent in the soil but root colonization by them is abundant $[32,33]$.

Unevenness of AM fungal distribution is ubiquitous in natural ecosystems. Large variation in spore density and species richness of AM fungi in different rhizosphere and roots has also been reported at many sites [34-38]. There are several possible reasons for this. Firstly, disparity in sporulation ability of different AM fungi species can result in unevenness of spore density [39]. Secondly, the occurrence of interspecific competition among AM fungi is possible in the soil and within roots [40]. Also seasonality, spatial and temporal variation, complex below ground structure, host-preference and disturbance are generally thought to coincide with the variation of AM fungi distribution and community structure [41-45]. For this study, sporulation ability, host-preference and complex below ground structure seem to be more influential in the distribution of mycorrhizal spores and community structure in orchard ecosystem.

\section{References}

1. Smith SE, Read DJ (2008) Mycorrhizal Symbiosis, 3rd ed. San Diego, CA: Academic Press.

2. Azcón-Aguilar C, Barea JM (1997) Applying mycorrhiza biotechnology to horticulture: significance and potentials. Sci Hortic 68: 1-24.

3. Garmendia I, Goicoechea N, Aguirreolea J (2004) Effectiveness of three Glomus species in protecting pepper (Capsicum annuum L.) against verticillium wilt. Biol Control 31: 296-305.

4. Mosse B (1972) Effects of different endogone strains on the growth of Paspalum notatum. Nature 239: 221-223.

5. Hayman D S (1982) Influence of soils and fertility on activity and survival of vesicular arbuscular mycorrhizal fungi. Phytopathology 72 : 1119- 1125 .

6. Fitter AH (1985) Functioning of vesicular arbuscular mycorrhizas under field conditions. New Phytologist 99: 257-265.

7. Hass IH, Menge JA (1990) Va-mycorrhizal fungi and soil characteristics in avocado (Persea americana Mill.) orchard soils. Plant and soil 127: 207-212.

8. van der Heijden, Marcel GA (2002) Arbuscular mycorrhizal fungi as a determinant of plant diversity: in search for underlying mechanisms and general principals. Mycorrhizal Ecology Ecological Studies 157: 243-265.

9. Burrows R, Pfleger $\mathrm{F}(2002)$ Arbuscular mycorrhizal fungi respond to increasing plant diversity.Can. J. Bot. 80: 120-130.

10. Kernaghan G, Widden P, Bergeron Y, Le'gare' S, Pare' D (2003).Biotic and abiotic factors affecting ectomycorrhizal diversity in boreal mixedwoods. Oikos 102: 497-505.

11. Philips JM, Hayman DS (1970) Improved procedures for clearing roots and staining parasitic and vesicular-arbuscular mycorrhizal fungi for rapid assessment of infection. Trans. Brit. Mycol. Soc. 55: 158-161.

12. Kormanik PP, Graw MC (1982) Quantification of vesicular arbuscular mycorrhizae in plant roots. In: Schenck NC (ed) methods and principles of mycorrhizal research. The American phytopathological Soceity, St. paul PP 37-45.

13. Giovannetti M, Mosse B (1980) An evaluation of techniques for measuring vesicular- arbuscular infection in roots, New Phytol 84: 489500.

14. Gerdemann JW, Nicolson TH (1963) Spores of mycorrhizal Endogone species extracted by wet sieving and decanting. Trans. Br. Mycol. Soc. 46: 235-244.

15. Thenmozhi R, Reshma T, Kavitha T, Madhusudhanan K, Praveen Kumar D (2011) Studies on vam colonization on selected medicinal plants. Archives of applied science research, 3: 445-449.

16. Utobo EB, Ogbodo EN, Nwogbaga AC (2011) Techniques for extraction and quantification of arbuscular mycorrhizal fungi. Libyan agriculture research center internation 2: 68-78.

17. Oehl F, Sieverdig E, Palenzuela J, Ineichen K, Alves da Silva G (2011) Advances in Glomeromycota taxonomy and classification. IMA Fungus 2: 191-199.

18. Hall I R, Fish BJ (1979) A key to Endogonaceae. Trans. Br. Mycol. Soc. 73: 261- 270.

19. Hall IR (1984) Taxonomy of VA mycorrhizal fungi. In: VA Mycorrhiza (Eds.) Powell, C.L.I. and Bagyaraj D.J. CRC Press, Boca Raton, FL, PP. 57-94.

20. Schenck NC, Perez (1987) Mannual for identification of VA- mycorrhizal fungi. University of florida, Gainesville, Florida, USA.

21. Morton JB (1988) Taxonomy of VA mycorrhizal fungi: Clasification, nomenclature, and identification. Mycotaxon 32: 267-324.

22. Morton JB, Benny G L (1990) Revised classification of arbuscular mycorrhizal fungi(Zygomycetes): A new order Glomales, two new suborders Glomineae and Gigasporineae and two new families Acaulosporaceae and Gigasporaceae with an emendation of Glomaceae. Mycotaxon 37: 471-491.

23. Schenck NC, Smith GS (1982) Additional new and unreported species of mycorrhizal fungi (Endogonaceae) from florida. Mycologia 74: 77-92. 
24. Blaszkowski J, Adamska I, Madej T (2002) Glomus lamellosum (Glomales,Zygomycota), an arbuscular mycorrhizal fungal species new for Poland and Europe. Mycotaxon 81: 281-292.

25. Blaszkowski J, Madej T, Tadych M (1998). Entrophosphora baltica sp. Nov. and Glomus fuegianum, two species in the glomales from Poland. Mycotaxon 68: 165-184.

26. Blaszkowski J, Tadych M, Madej T, Adamska I (2001) Arbuscular mycorrhizal fungi (Glomales, Zygomycota) of Israeli soils. Mat. II Polsko- Israelskiej Konf. Nauk. Nt. "Gospodarowanie zasobami wodnymi I nawadnianie roslin uprawnych”. Przeglad naukowy Wydz. Inz. Ksztalt. Srod. 22: 8-27.

27. Koske RE, Gemma JN (1997) Mycorrhizae and succession in plantings of beachgrass in sand dunes. Amer. J. Bot. 84: 118-130.

28. Koide RT, Mosse B (2004) A history of research on arbuscular mycorrhiza. Mycorrhiza 14: 145-163.

29. Hepper CM (1984) Isolation and culture of VA mycorrhizal (VAM) fungi. In: Powell CL, Bagyaraj DJ (eds) VA mycorrhizae. CRC Press, Florida, pp 95-112.

30. Moreira-Souza M, Trufem SFB, Gomes-da-Costa SM, Cardoso EJBN (2003) Arbuscular mycorrhizal fungi associated with Araucaria angustifolia (Bert.) O. Ktze. Mycorrhiza 13: 211-215.

31. Zhao DD, Zhao ZW (2007) Biodiversity of arbuscular mycorrhizal fung in the hot-dry valley of the Jinsha River, southwest China. Applied Soil Ecology 37: 118-128.

32. Jasper DA, Abbott LK, Robson AD (1993) The survival of infective hyphae of vesicular-arbuscular fungi in dry soil: an interaction with sporulation. New Phytol 124: 473-479.

33. Clapp JP, Young JPW, Merry weather JW, Fitter AH (1995) Diversity of fungal symbionts in arbuscular mycorrhizas from a natural community. New Phytol 130: 259-265.

34. Azco'n-Aguilar C, Palenzuela J, Rolda'n A, Bautista S, Vallejo R, Bareaz, et al (2003) Analysis of the mycorrhizal potential in the rhizosphere of representative plant species from desertification threatened Mediterranean shrublands. Appl Soil Ecol 22: 29-37.
35. Zhao ZW, Wang GH, Yang L (2003) Biodiversity of arbuscular mycorrhizal fungi in a tropical rainforest of Xishuangbanna, southwest China. Fungal Divers 13: 233-242.

36. Pande M, Tarafdar JC (2004) Arbuscular mycorrhizal fungal diversity in neem-based agroforestry systems in Rajasthan. Appl Soil Ecol 26: 233 241.

37. Wang FY, Liu RJ, Lin XG, Zhou JM (2004) Arbuscular mycorrhizal status of wild plants in saline-alkaline soils of the Yellow River Delta. Mycorrhiza 14: 133-137.

38. Radhika KP, Rogrigues BF (2010) Arbuscular mycorrhizal fungal diversity in some commonly occurring medicinal plants of Western Ghats, Goa region. J For Res 21: 45-52.

39. Bever JD, Morton JB, Antonovics J, Schultz PA (1996) Host dependent sporulation and species diversity of arbuscular mycorrhizal fungi in a mown grassland. J Ecol 84: 71-82.

40. Brundrett MC, Kendrick B (1990) The roots and mycorrhizas of herbaceous woodland plants II. Structural aspects of morphology. New Phytol 114: 469-479.

41. Guadarrama PA , lvarez-Sa'nchez FJ (1999) Abundance of arbuscular mycorrhizal fungi spores in different environments in a tropical rain forest, Veracruz, Mexico. Mycorrhiza 8: 267-270.

42. Bever JD, Schultz PA, Pringle A, Morton JB (2001) Arbuscular mycorrhizal fungi: more diverse than meets the eye, and the ecological tale of why. Bioscience 51: 923-931.

43. Zhao ZW, Xia YM, Qin XZ, Li XW, Cheng LZ, et al.(2001) Arbuscular mycorrhizal status of plants and the spore density of arbuscular mycorrhizal fungi in the tropical rain forest of Xishuangbanna, southwest China. Mycorrhiza 11: 159-164.

44. Husband R, Herre EA, Young JPW (2002) Temporal variation in the arbuscular mycorrhizal communities colonizing seedlings in a tropical forest. FEMS Microbiol Ecol 42: 131-136.

45. Muthukumar T, Udaiyan K (2002) Seasonality of vesicular-arbuscular mycorrhizae in sedges in a semi-arid tropical grassland. Acta Oecologica Int J Ecol 23: 337-347. 